\section{High frequency jet ventilation via a tracheoscope for endo- bronchial laser surgery}

\begin{abstract}
Palliative surgery of malignant endobronchial tumours is associated with various anaesthetic risks. A technique is described using a neodymium:yttrium-aluminium-garnet (Nd:YAG) laser in combination with a special tracheoscope and high frequency jet ventilation (HFJV). The purpose of this technique is to provide separation of anaesthetic and surgical manipulations, good conditions of ventilation and easy access to the lungs for the surgeon. We present our experience with 14 adult patients in whom large endobronchial neoplasms were resected using this technique under intravenous anaesthesia and muscle relaxation. Careful perioperative monitoring and a good outcome allowed us to conclude that this set-up may contribute to improving efficiency and safety of endoscopic resections of endobronchial andlor endotracheal tumours
\end{abstract}

La chirurgie palliative des tumeurs malignes et endonbronchiques est associée d̀ des risques anesthésiques variés. Une technique est décrite utilisant un laser (Nd:YAG) en combinaison avec un trachéoscope spécial et une ventilation à haute fréquence (HFJV). Le but de cette technique est de fournir une séparation des manipulations anesthésiques et chirurgicales, offrir de bonnes conditions de ventilation et un accès facile aux poumons pour le chirurgien. On présente notre expérience avec 14 patients adulte chez qui des larges tumeurs endobronchiques furent réséquées utilisant cette technique en combinaison avec une anesthésie intraveineuse et une relaxation musculaire. Une

\section{Key words}

ANAESTHETIC TECHNIQUES: intravenous;

EQUIPMENT: lasers, Nd:YAG, tracheoscope, ventilators, high frequency jet;

SURGERY: laser, endobronchial;

VENTILATION: high frequency.

From the Department of Anaesthesia* and Otorhinolaryngology, $†$ University of Basel, Kantonsspital, $\mathrm{CH}-4031$ Basel, Switzerland.

Address correspondence to: Dr. M. Schneider, Department of Anaesthesia, University of Basel, Kantonsspital, CH-4031 Basel, Switzerland. surveillance méticuleuse en période périopératoire et des bons résultats nous ont permis de conclure que cette technique peut contribuer à améliorer l'efficacité et la sécurité des résections par endoscopie des tumeurs endobronchiques etlou endotrachéales.

The increasing incidence of bronchial carcinoma ${ }^{1}$ coupled with the difficulty in obtaining curative therapy for this disease has resulted in greater emphasis being placed on various types of palliative therapy such as endoscopic laser surgery. Since its introduction into clinical practice in 1972, the advantages and risks of laser techniques for endobronchial surgery have been documented. ${ }^{2-4}$

Originally, a carbon dioxide laser was introduced and its use was restricted only by the requirement for direct visualisation of the lesion. ${ }^{4}$ The development of a neodymium:yttrium-aluminium-garnet (Nd:YAG) laser increased the indications, efficacy and safety of endoscopic tumour resections. 5 The main advantage of this laser is that the invisible beam is transmitted through flexible optic fibres thus permitting surgical access to even more distal points of the tracheobronchial tree.

Several methods for endoscopic resections exist. The use of flexible fibrescopes for the resection of larger tumours is not recommended. ${ }^{6,7}$ Commonly a rigid bronchoscope with an instrument guide for the laser probe is utilised. ${ }^{7,8}$ This ensures direct access to the operative field and good conditions for suction and coagulation. By connecting a fresh gas delivery system to the ventilating attachment, the bronchoscope is used to allow ventilation of the patient's lungs. ${ }^{9}, 10$ Occasionally, hypoventilation may occur when the bronchoscope is moved endobronchially and the bulk of ventilation is directed towards the obstructed lung resulting in critical reduction of gas exchange within the nonobstructed lung (Figure 1).

In addition, frequent manipulations of the bronchoscope may be necessary and lead to constantly changing conditions of ventilation. Finally, temporary introduction or removal of instruments may interfere with oxygenation and carbon dioxide elimination.

In order to minimize the risks of hypoxaemia and 


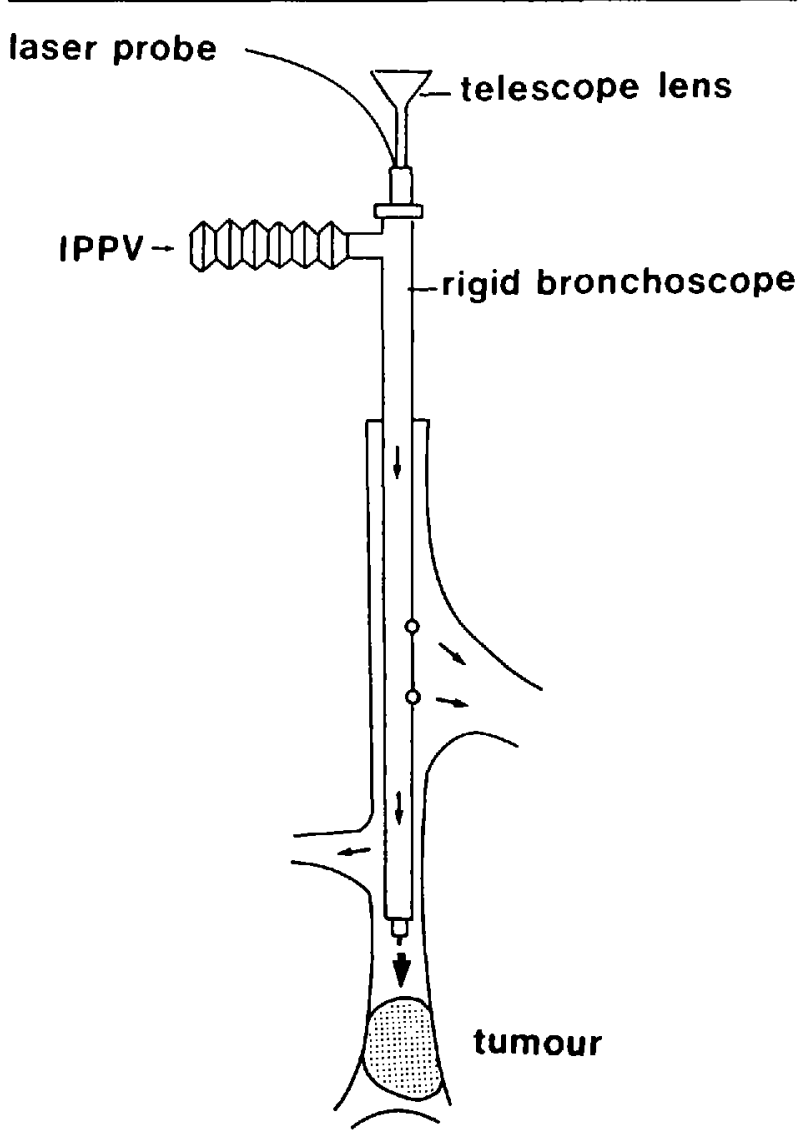

FIGURE 1 Schematic representation of endobronchial tumour resection in the right bronchus intermedius, using a rigid bronchoscope and a Nd:YAG laser. Ventilation and surgical procedure are limited and fresh gas flow is mainly directed towards the obstructed right lung (arrows).

hypercapnia, a technique was adapted which we previously used for $\mathrm{CO}_{2}$ laser surgery. It partially separates anaesthetic airway management from the surgical procedure by using high frequency jet ventilation (HFJV) in combination with a rigid tracheoscope.

\section{Methods}

With informed consent 14 adult patients scheduled for tracheobronchial endoscopic surgery were treated using a Nd:YAG laser (Cooper Lasersonic, Model 6000). Preoperative medications for control of bronchospastic and cardiovascular diseases were continued and administered together with the premedication.

Before starting anaesthesia, arterial, peripheral, and central venous lines were inserted percutaneously. These were utilised for continuous arterial pressure recording, arterial blood gas determination, and intravenous fluid and drug administration. In addition, heart rate and rhythm (lead $V_{5}$ of ECG), arterial oxygen saturation
$\left(\mathrm{SaO}_{2}\right)$ (Nellcor N100 pulse oximeter with finger-tip probe), and transcutaneous $\mathrm{CO}_{2}$ tension $\left(\mathrm{PCO}_{2}\right)$ (Kontron Instruments MicroGas 7640 with $\mathrm{CO}_{2}$ electrode, heated to $43^{\circ} \mathrm{C}$, and placed on the thorax) were controlled. Furthermore, neuromuscular relaxation (Bard Biomedical, twitch monitor), temperature, and breath sounds (precordial stethoscope) were monitored.

After preoxygenation by mask, anaesthesia was induced using thiopentone or etomidate and maintained with repeated doses of midazolam, fentanyl and/or alfentanil. Neuromuscular blockade was achieved with atracurium or vecuronium. After positioning of the patient, a laser tracheoscope (Karl Storz 85907T Swiss Model) was introduced as far as possible into the trachea. A small anchoring device at the proximal end of the tracheoscope was used to position a metal tube for HFJV. The jet cannula ( $2 \mathrm{~mm}$ internal diameter, $15 \mathrm{~cm}$ length) was connected by a noncompliant plastic tube $(5 \mathrm{~mm}$ internal diameter, $200 \mathrm{~cm}$ length) to the jet ventilator (MK 600 Acutronic Medical Systems AG, Switzerland). Pure oxygen was delivered. Driving pressure, respiratory frequency and inspiratory-expiratory ratio (I/E) could be adjusted independently. Based on earlier clinical experience, HFJV was started with a driving pressure of 30 psi at a frequency of $150 \cdot \mathrm{min}^{-1}$ and with an $\mathrm{V} / \mathrm{E}$ ratio of $40 / 60$ per cent. If neccessary, these primary conditions were adjusted in order to maintain a normal $\mathrm{PCO}_{2}$ and to prevent hypoxaemia. If hypoventilation was not corrected by changing the HFJV setting, a standard orotracheal tube with cuff (internal diameter (ID) 4-5 mm) was passed through the tracheoscope to perform manual hyperventilation and, when necessary, to apply PEEP.

For endoscopic surgery we used an instrument guide for the laser bronchoscope (Karl Storz 10317EF) with distinct channels for Hopkins-telescope lenses (Karl Storz Endoscopy), for a suction catheter, and for the laser probe. The Nd:YAG laser was set at $40 \mathrm{~W}$ applied in pulses of $0.5-1 \mathrm{sec}^{8}$ To clear the operative field, a metal suction tube or various types of forceps were introduced under direct vision through the tracheoscope, or under control with a telescope (Figure 2). When necessary, small residues of more peripherally located tumours were coagulated using a fibrescope (Olympus BF IT20).

At the end of the procedure, the tracheoscope was removed and the trachea was intubated with a cuffed tracheal tube. As soon as spontaneous breathing was sufficient, the tube was removed after careful tracheal toilet and reversal of residual muscular relaxation with edrophonium or neostigmine.

\section{Results}

Fourteen patients with obstructing malignant tumours of the tracheobronchial tree were admitted for palliative 


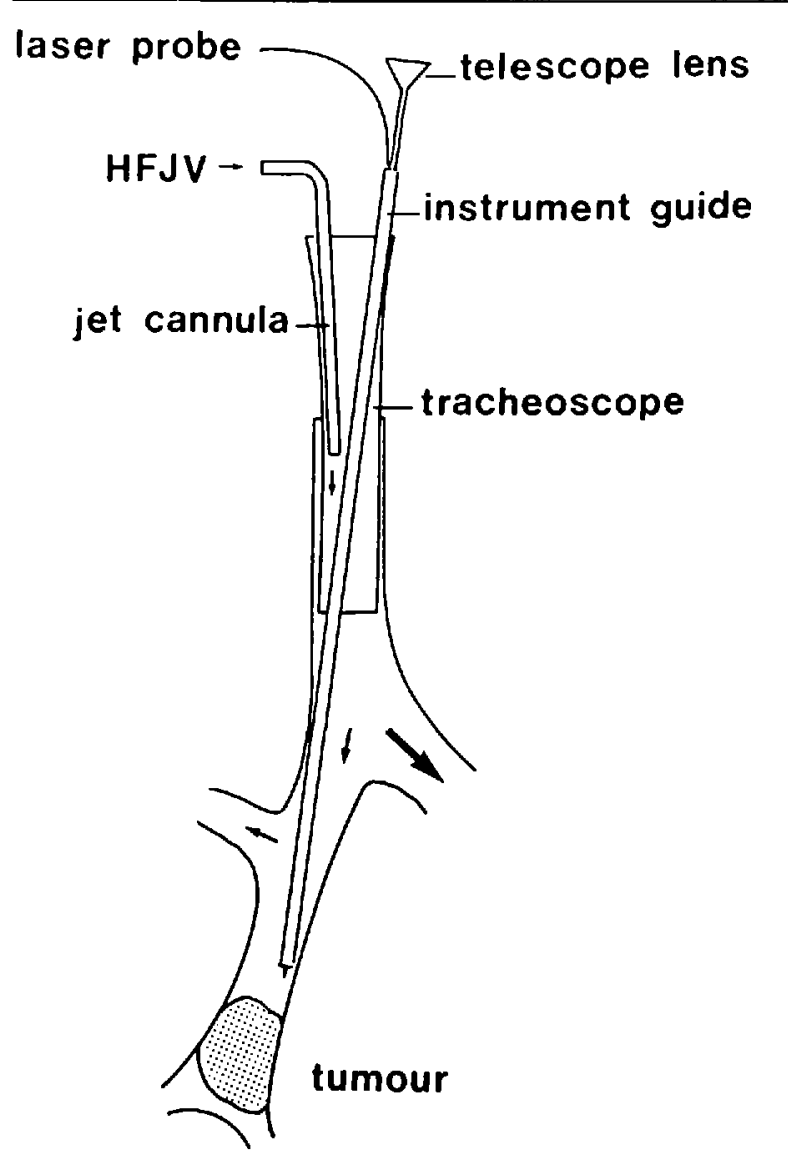

FIGURE 2 Schematic representation of the technique using a tracheoscope, HFJV and an instrument guide for the Nd:YAG laser probe. Ventilation and surgical procedure are separated and fresh gas flow is directed towards both lungs (arrows). Quick access to both sides of the lungs is improved

endoscopic surgery. They ranged in age from 48 to $74 \mathrm{yr}$ (mean $64.5 \mathrm{yr}$ ) and belonged to ASA physical status II or III. The size and location of the tumour had been determined in all patients preoperatively by fibreoptic and radiological examination. There was always evidence of poststenotic atelectasis and/or pneumonia. Eleven of the tumours were located in the primary bronchi alone, three showed an extensive growth towards the trachea, and two were found more peripherally in secondary bronchi. Severe dyspnoea at rest was always present. Three of the patients had already undergone previous lung surgery.

For tumour resection a Nd:YAG laser was used. Procedure times ranged from 35 to 280 min (mean 95 $\min$ ). There was no perioperative mortality and the trachea of all but one of the patients could be extubated without difficulty and the patients returned to the ward. The latter, who had been suffering from coronary artery disease, had to be transferred to the ICU for ventilation and haemodynamic control after an intraoperative sub-

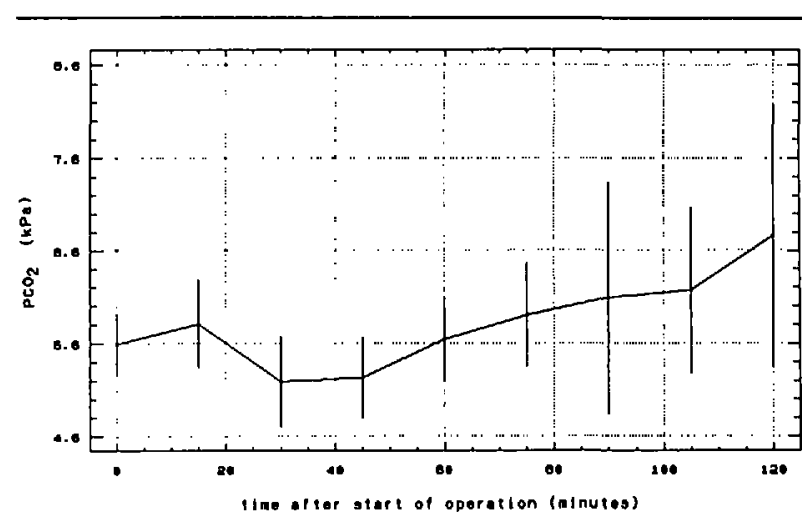

FIGURE $3 \mathrm{PCO}_{2}$, as measured by a transcutaneous probe, during HFJV started after positioning of a laser tracheoscope (time 0 ). Indicated are mean values $\pm \mathrm{SE}$.

endocardial infarction complicated by ventricular tachycardia.

Using HFJV with a ventilatory pattern based on blood gas tensions, severe hypoventilation $\left(\mathrm{PCO}_{2}>8 \mathrm{kPa}\right)$ occurred in only one of the patients and was treated by manual hyperventilation after tracheal intubation $(4 \mathrm{~mm}$ tube with cuff) inserted through the tracheoscope. Otherwise, the $\mathrm{PCO}_{2}$ was held within a range of $4-8 \mathrm{kPa}$ (Figure 3). Severe hypoxaemia $\left(\mathrm{SaO}_{2}<90\right.$ per cent) was not observed, although oxygenation varied during surgery (Figure 4). Disappearance or improvement of the dyspnoea was observed in all patients after surgery.

\section{Discussion}

Adequate ventilation is a major concern during endoscopic resections of obstructing tumours of the tracheobronchial tree. Due to heavy smoking and a reduction of functional lung tissue by tumour infiltration or previous surgical resection, obstructive and restrictive pulmonary disease is a common finding in these patients. Thus, it is of paramount importance to reduce the danger of hypoventilation during endoscopic laser surgery which may be accompanied by a considerable mortality rate. "

By choosing HFJV for endoscopic Nd: YAG operations it is possible to separate partially ventilation from surgical manipulations. The laser tracheoscope with a metallic injector cannula at its side provides constant conditions of oxygen supply and air entrainment. ${ }^{12}$ Carbon dioxide elimination is generally easily controllable by adjusting the ventilator setting. ${ }^{12,13}$ In these patients oxygenation was usually better under HFJV than with spontaneous breathing, due to recruitment of collapsed alveoli by intrathoracic gas trapping, "PEEP effect"12 and, therefore, reduction of the shunt fraction. ${ }^{14}$ Furthermore, the surgeon profits from constant direct access to the site of operation. Manoeuvres like changing and cleaning of in- 


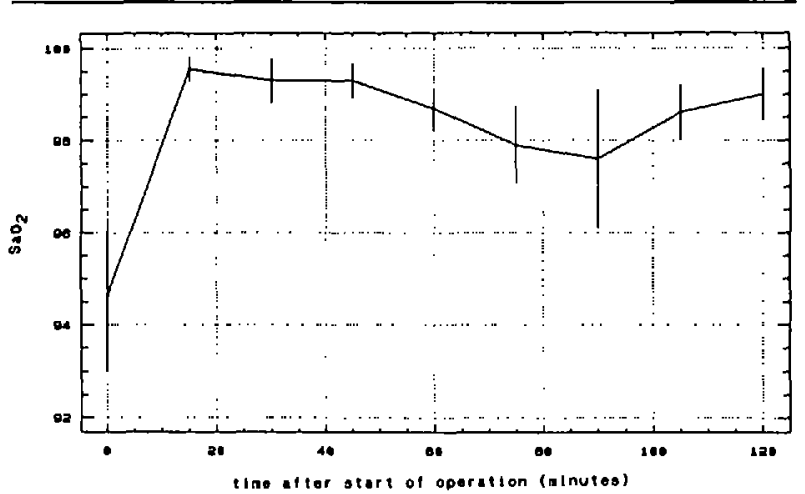

FlGURE $4 \mathrm{SaO}_{2}$, as measured by pulse oximetry, during $\mathrm{HFJV}$ started after positioning of a laser tracheoscope (time 0 ). Indicated are mean values $\pm S E$.

struments can be done readily and without delay. Suction tubes, forceps for mechanical tumour reduction and fibrescopes can be utilised as well without dangerous interference with ventilation. The constant direct vision of the carina serves as a basis for preventing an overflow of blood or mucus from the operated to the nonoperated lung. In the event of a major haemorrhage, the nonoperated lung can be intubated immediately through the tracheoscope with a long cuffed endobronchial tube of appropriate diameter (ID 4-5). Thus the safety of endobronchial laser surgery is increased and the risk of hypoxaemia reduced.

A major concern of laser surgery, the tracheal tube fire, is virtually eliminated by the use of a metallic injector cannula for HFJV, as is the problem of choosing a "safe $\mathrm{FIO}_{2}$ " to minimise the incidence of tube ignition. 3,4,15

In institutions without equipment for HFJV, low frequency jet ventilation (LFJV) through the tracheoscope may be considered as an alternative. Using a bronchoscope and a Sanders injector, LFJV at a frequency of $20 \cdot \mathrm{min}^{-1}$ is comparable with HFJV in terms of alveolar ventilation during bronchoscopy and bronchoscopic laser surgery of patients with tracheobronchial stenosis. ${ }^{16,17}$ As long as the tip of the bronchoscope is located within the trachea, both methods of ventilation are interchangeable and safe ${ }^{17}$ However, from a surgical point of view, HFJV often is the first choice because the tracheo-bronchial wall remains almost immobile.

Constant monitoring of arterial blood gases and $\mathrm{SaO}_{2}$ is mandatory during tracheal and endobronchial surgery. Short-term changes of oxygenation are detected by pulse oximetry, ventilation is adjusted by blood gas analysis and a transcutaneous measuring probe for carbon dioxide. ${ }^{16}$ Thus, the risk of hypoventilation is reduced and resections of even extensive tumours can be carried out in one session.

In summary, we have described a technique for
Nd:YAG laser surgery of obstructing tumours within the major airways using, instead of a rigid bronchoscope, a tracheoscope and HFJV (Figure 2). In our experience, the method appears to be safe and effective and compartmentalises to some degree anaesthetic management from surgical manipulations. Nevertheless, close cooperation between the surgeon and the anaesthetist is very important to guarantee a smooth and secure progress of the operation. Using the technique, perioperative morbidity was low (one patient with pre-existing coronary artery disease suffered a subendocardial myocardial infarction), and mortality was zero.

\section{Acknowledgements}

The authors gratefully acknowledge the assistance of Dr. Burnell R. Brown for his review of the manuscript. We also wish to thank Barbara Funk for the preparation of the figures and Joan Etlinger for her excellent assistance in manuscript preparation.

\section{References}

1 World Health Statistics Annual 1987, Geneva: World Health Organization, 30-2.

2 Mitchell MM. Anesthesia for laser surgery: general considerations. In: Barash PG (Ed.). ASA Refresher Courses in Anesthesiology. Park Ridge, Illinois: American Society of Anesthesiologists, Inc, 1986; 14: 159-69.

3 Wittels SH. Anesthesia for laser surgery. Current Reviews in Clinical Anesthesia 1985; 8: 3-7.

4 Hermens JM, Bennett MJ, Hirshman CA. Anesthesia for laser surgery. Anesth Analg 1983; 62: 218-29.

5 Vourc'h $G$, Tannieres $M L$, Toty $L$, Personne $C$. Anaesthetic management of tracheal surgery using the neodymium-yttrium-aluminium-garnet laser. $\mathrm{Br} \mathrm{J}$ Anaesth 1980; 52: 993-7.

6 George PJM, Garrett CPO, Nixon C, Hetrel MR, Nanson $E M$, Milliard FOC. Laser treatment for tracheobronchial tumours: local or general anaesthesia? Thorax 1987; 42: 656-60.

7 Dumon JF. Applications of the neodymium-yttriumaluminium-garnet laser in bronchiology. In: Shapshay SM (Ed.). Endoscopic Laser Surgery Handbook. New York: Dekker, 1987: 189-208.

8 Podvinec M, Pfaltz CR, Palas TAR. Probleme und neue Entwicklungen in der endotrachealen Laser Chirurgic. In: Kellerhals B, Fisch U, Mann J, Montandon P, de Reynier JP, Terrier G (Eds.). Aktuelle probleme der Otorhinolaryngologie 6. Bern: Hans Huber Verlag, 1983; 24-8.

9 Perera ER, Mallon JS. General anaesthetic management for laser resection of central airway lesions in 85 procedures. Can J Anacsth 1987; 34: 383-7. 
10 Shapshay SM, Dumon JF, Beamis JF. Endoscopic treatment of tracheobronchial malignancy: experience with Nd-YAG and $\mathrm{CO}_{2}$ lasers in 506 operations. Otolaryngol Head Neck Surg 1985; 93: 205-10.

11 Warner ME, Warner MA, Leonard PF. Anesthesia for neodymium-YAG (Nd-YAG) laser resection of major airway obstructing tumors. Anesthesiology 1984; 60: 230-2.

12 Rouby $J J$, Simmeau G, Benhamou $D$ et al. Factors influencing pulmonary volumes and $\mathrm{CO}_{2}$ elimination during high-frequency jet ventilation. Anesthesiology 1985; 63: 473-82.

13 Wetzel RC, Gioia FR. High frequency ventilation. Pediatr Clin North Am 1987; 34: 15-38.

14 Smith BE, Scott PV, Fischer HBJ. High frequency jet ventilation in intensive carc - a review of 63 patients. Anaesthesia 1988; 43: 497-505.

15 Geffin B, Shapshay SM, Bellack GS, Hobin K, Setzer $S E$. Flammability of endotracheal tubes during $\mathrm{Nd}$ YAG laser application in the airway. Anesthesiology 1986; 65: 511-5.

16 Vourc'h G, Fischler M, Michon F, Melchior JC, Seigneur $F$. High frequency jet ventilation $v$. manual jet ventilation during bronchoscopy in patients with tracheo-bronchial stenosis. Br J Anaesth 1983; 55: 969-72.

17 Vourc'h G, Fischler M, Michon F, Melchior JC, Seigneur $F$. Manual jet ventilation v. high frequency jet ventilation during laser resection of tracheo-bronchial stenosis. $\mathrm{Br}$ J Anacsth 1983; 55: 973-5. 